\title{
Defining Microgames in Education Context
}

\author{
https://doi.org/10.3991/ijet.v16i22.20929 \\ Imam Fitri Rahmadi ${ }^{(\bowtie)}$, Zsolt Lavicza, Tony Houghton \\ Johannes Kepler Universität Linz, Linz, Austria \\ imam.rahmadi@jku.at
}

\begin{abstract}
The concept of microgaming in education is relatively new and it has evident potential for supporting learning in various learning environments. However, there is little consensus in the education literature on how microgames are defined. The present article proposes a conceptual definition of microgames by considering related terms and learning approaches in education. Microgames in education context are defined as very small and short games that provide brief engagement and meaningful experience for players, support learning and instruction toward specific objectives, and integrate with existing resources. This article further elaborates the key definition elements to indicate microgame characteristics and provides some examples to demonstrate the kinds of games that fit this definition. The proposed definition acts as a fundamental starting point to study microgames for educational purposes in the future.
\end{abstract}

Keywords - microgames, microgame-based learning, serious games

\section{Introduction}

The concept of microgaming - often referring to the use of very small games for particular purposes - in education is relatively new and it has evident potential for supporting learning in school, workplace, and general environments. Microgames are useful for supplementing, reinforcing, and integrating knowledge acquisition in schools [1], [2]. Harnessing microgames in workforce training encourages high engagement and was recognised by workers as a novel approach for situated and experiential learning [3]. Moreover, microgames can appeal to the general public to interact with and gain a better understanding of cultural heritage [4]. From these three cases, it appears that microgames could be integrated into various learning environments.

There is little consensus in the education literature on how microgames are defined. Although the term itself has been established in some articles, there is no current single agreed definition to the concept. In fact, some scholarly articles on microgames [4] and mini-games [5] were written without giving any definition. Brom [1] in the context of formal education defined microgames as "relatively simple computer games that do not require special skills to play and that challenge players with clearly defined goals reachable within minutes or tens of minutes of game-play." This definition seems less applicable in the context of informal education for workforces and so Lukosch [3] created their own definition of microgames as "a simulation game that can be played in a short 
time period and that starts from a specific problem in the organisation defined by a problem owner." Operational definitions in the specific study context are essential but not sufficient. Consequently, a conceptual definition that could be widely accepted in general education is needed for gaining a universal understanding.

In addition to the various definitions of microgames, the term microgames have different connotations in a general context compared to that of education. It is often associated with board games and wargames packaged in a small set [6] such as Checkers, Cluedo, Tic-tac-toe, Dungeons \& Dragons, Flames of War, and Hearts of Iron IV. It is also associated with simple digital minigames like Super Smash Bros, Wario Land, Super Mario, Donkey Kong 64, and Nintendo Land [7]. Furthermore, the term for expressing the idea was written in various ways such as micro games, micro-games, minigame, and mini-game. This evidence strengthens the need for providing a proper definition of microgames in an educational context.

Having a conceptual definition of microgames brings multiple benefits. First, the definition would be fruitful for effectively introducing microgames to educators, learners, and other wider audiences in education sectors. It prevents misconception of microgames for teaching and learning purposes as the definition of microgames in general context has a relatively different articulation. Second, the meaning of microgames proposed in this article tries to accommodate various learning environments so that it is acceptable for either formal or informal education. Finally, the explanation serves as a base for studying microgames in the future. It is also intended to be useful for researchers to start investigating or exploring microgames in education. Scholars may take advantage of the definition to study microgames in their own learning context.

Educational microgames have some advantages compared to learning games in general. As the games are very small and short, it can be considered as viable teaching and learning tools easily integrated into existing learning structures and resources [8]. Those games are playable during the limited learning time and strict school curriculum with no prior knowledge about the game mechanics to play such games [1], [9], [10]. Conversely, inserting regular serious games into learning is somehow always problematic. The games take a fairly long time to play and players need to learn particular game mechanics before playing [11]. Furthermore, practicing game-based learning requires high technologies in which the technologies are often not available in schools [12], [13]. Therefore, microgame-based learning appears promising to facilitate knowledge and skill acquisition in schools and other learning environments.

The present article proposes a conceptual definition of microgames by considering related terms and learning approaches in education. The term microgames in the sense of board game and wargame or similar games is excluded from the construction. Additionally, some examples of microgames are provided to show the kinds of games that fit the definition. This article concludes with some reflections highlighting prominent issues from the definition and its elements elaboration. 


\section{Terms related to microgames in education}

The word microgames consists of two different terms namely micro and games. These are elaborated in the following sub-headings focusing on their educational context.

\subsection{Micro}

The Merriam-Webster dictionary defines micro as "very small" and "involving minute quantities or variations." [14] Furthermore, dictionary.com describes it as "extremely small" and "minute in scope or capability" (adjective) and "anything extremely small in scope or capability" (noun) [15]. Both dictionaries state that micro is extremely small in scale and short in duration.

Micro is a general term. It is also part of a framework consisting of micro, meso, and macro. The micro-macro framework has been used in many disciplines including sociology, economics, and philosophy. For instance, there are concepts of microeconomics and macroeconomics in economics, or micro-meso-macro economics [16]. However, the micro, meso, and macro framework can be quite different from one discipline to another [17].

The concept of micro in education was explained by Hug [18] and Hug \& Friesen [19] state that micro level means micro content for more individualized learning structured by learning objects. The content might be adjusted based upon the abilities and interests of each learner to tailor more personalized learning with respect to their different needs. The meso and macro levels of learning are structured by topics or lessons and courses or curricular structures. In both learning levels, the content is less individualised owing to the broad structure for more general learners. A simple example was given in the context of language learning, where the micro aspects are illustrated by learning vocabularies, phrases, and sentences. Further, a single letter learning in linguistics is also part of the micro content concept.

\subsection{Games}

Games are very familiar in everyday life. From an early age, children get used to playing some games benefiting their cognitive and psychomotor developments. In 1952, an American mathematician well known for his works on mathematical logic and game theory John Charles Chenoweth McKinsey argued that game is "a set of rules and conventions for playing" [20]. In his book entitled Introduction to the Theory of Games, he describes and distinguishes between game and play, in which both have ambiguous meanings.

Ambiguous meaning between game and play was further clarified by Caillois [21] states that "the game must be taken back within the agreed boundaries" while "play must be defined as a free and voluntary activity, a source of joy, and amusement." For example, a game starts and ends at a given signal with duration fixed in advance. The game is not interrupted or abandoned without a major reason. Should there be occasion to do so, the game is prolonged by agreement between the contestants or by the decision 
of an umpire. Thus, games are a subset of playing and play is a component of games [22]. Games could be likened to simulation. The key distinction is that simulations propose to represent reality whilst games do not. There are six key dimensions that characterize games: fantasy, rules/goals, sensory stimuli, challenge, mystery, and control [23]. Some game features could be included in simulations. Simulations that incorporate these features become more game-like.

Games definition is dynamically changing over time. After studying eight game definitions provided by previous scholars, Salen [22] synthesises and provides a definition of games as "a system in which players engage in an artificial conflict, defined by rules, that results in a quantifiable outcome." The Encyclopedia of Terminology for Educational Communications and Technology [24] refers the word games to the digital gamebased learning owing to many traditional games that have been transformed into digital games.

\section{Learning approaches related to microgames in education}

Microgames are defined under the learning approaches of serious games and microlearning. Those learning approaches influence how the definition is formulated. These are elaborated below.

\subsection{Serious games}

Serious games are defined as games designed and developed specifically for learning purposes [24]. This field is extensively discussed in a book called Serious Games by Abt in 1970. Serious games offer a rich field for a risk-free, active exploration of serious intellectual and social problems [25]. The term serious is intended to reflect the purpose and reason of the game regardless of content. This purpose, from both computer games and educational simulation genres, is using the artistic medium of games for delivering a message, teaching a lesson, or providing another educational experience [26]. Serious games provide users with fun and meaningful experiences reaching up to the emotional level as well as offer immediate feedback and adaptability resulting in the higher goals achievement level at the time that is hard to improve learner's motivation in traditional ways [27]. The power of serious games is in the ability to create dedicated games content for learning rather than utilising existing leisure games [28].

Serious games have similarities in the components and other design issues with entertainment games [29], [26]. According to Mildner \& Mueller [29], games in serious or just entertaining ways share common elements including play, rules, storytelling, social factors, and learning. In addition, Michael \& Chen [26] points out that both game types have rules, simulate behaviors, accept input from the player, and provide feedback within the context of rules and behaviors. However, it does not mean that serious and leisure games are the same. Serious games focus on learning objectives whilst for entertainment games; fun is the most important aspect [30].

Another important issue in serious games design is about the adaptability and userfriendly aspects [31]. Serious games need to be easily integrated into existing lesson 
plans and course materials because they are a teaching tool and not substitutes for teachers and trainers [26]. Being adaptable to a variety of classroom and training situations as well as being easy to use are the main points of success in designing and integrating serious games into learning and instruction processes. Furthermore, the practice of game-based learning should contain briefing, playing, and debriefing activities [32], [33]. Players have to know the game's goals in relation to intended learning objectives and discuss what has been learnt from playing.

\subsection{Microlearning}

A book entitled Microlearning: Short and Sweet recently written by Kapp and Defelice in 2019 provides a definition as well as guidance of microlearning. The definition is "an instructional unit that provides a short engagement in an activity intentionally designed to elicit a specific outcome from the participant" [34]. Its definition was synthesised from five previous definitions created by other scholars. This definition focuses on the short engagement, brief experience, and focused outcome beyond a timeframe and content in which the previous definitions addressed. In addition, the absence of engagement eliminates the value of microlearning. No exact number of minutes is universally agreed. It depends on the instructional needs and goals. According to Kapp \& Defelice [34], microlearning should be integrated to the meso and macro structures of learning formally or informally. Informal integration of microlearning is based on learners' self-motivation to learn or master something while formal microlearning supports the larger organisational learning ecosystem.

There are multiple reasons for integrating microlearning into learning and instruction. Microlearning offers flexible and dynamic alternatives which are needed in the light of medial, societal and environmental changes [18] and also offers students the opportunity to more easily absorb and retain the information provided by the course lessons and activities which are more manageable and digestible [35]. Microlearning facilitates self-directed lifelong learning, enables individuals to stay up-to-date in today's knowledge society and offers a viable supplement to more time-consuming and formalized modes of learning [36]. Last but not least, microlearning is a new way of responding to the necessity of work-based learning, lifelong learning, personal learning, and much more [37].

Designing engaging and meaningful microlearning experiences may require advanced technologies and contents [38] that should be taken into account seriously. The technology requirements include; 1) highly transferable and unobtrusive of the learner's activities; 2) easily available and user-friendly; 3) persistent learning environment; 4) useful for enhancing different activities; 5) individual as well as shareable; and 6) adaptable and/or adaptive to learners' needs. Its contents should promote the acquisition of basic skills, foster the development of creativity skills, and capitalise on the learner's communication abilities. There are many kinds of microlearning activities, such as viewing a flashcard, watching a short video, listening to a podcast, composing a short poem, answering questions in quizzes, and playing microgames. 


\section{The proposed definition of microgames in education}

Related terms and learning approaches have been discussed and synthesised resulting in the following key definitions and characteristics as well as keywords included in the definition and its elaboration. The Table 1 summarises the terms and learning approaches associated with the key definitions and characteristics, and the included keywords.

Table 1. Key definitions and characteristics from the terms and learning approaches

\begin{tabular}{|c|c|c|}
\hline $\begin{array}{l}\text { Terms and learning } \\
\text { approaches }\end{array}$ & Key definitions and characteristics & $\begin{array}{l}\text { Keywords included in the defi- } \\
\text { nition and elaboration }\end{array}$ \\
\hline \multirow{2}{*}{ Micro } & Very small and short [14] & Very small and short \\
\hline & Micro content with specific objectives [18], [19] & Specific objectives \\
\hline \multirow[b]{2}{*}{ Games } & Set of rules and conventions for playing [20] & Rules and conventions \\
\hline & $\begin{array}{l}\text { Contains fantasy, rules/goals, sensory stimuli, } \\
\text { challenge, mystery, and control [23] }\end{array}$ & $\begin{array}{l}\text { Fantasy, rules or goals, sensory } \\
\text { stimuli, challenge, mystery, and } \\
\text { control }\end{array}$ \\
\hline \multirow{4}{*}{ Serious Games } & $\begin{array}{c}\text { Designed and developed specifically for learning } \\
\text { purposes [24] }\end{array}$ & Designed for learning purposes \\
\hline & Focus on the important element of learning [30] & Focus on the element of learning \\
\hline & $\begin{array}{c}\text { Provide users with meaningful experiences reach- } \\
\text { ing up to the emotional level [27] }\end{array}$ & Meaningful experiences \\
\hline & $\begin{array}{c}\text { Need to be easily integrated into existing lesson } \\
\text { plans and course material [26] }\end{array}$ & Should be integrated \\
\hline \multirow{3}{*}{ Microlearning } & $\begin{array}{c}\text { Provides short engagement, brief experience, and } \\
\text { focused outcome [34] }\end{array}$ & Short, brief and focused \\
\hline & \begin{tabular}{|c|} 
Should be integrated to the meso and macro \\
structures of learning formally or informally [34]
\end{tabular} & Should be integrated \\
\hline & $\begin{array}{c}\text { Offers a viable supplement to more time-consum- } \\
\text { ing and formalized modes of learning [36] }\end{array}$ & A viable supplement for learning \\
\hline
\end{tabular}

Table 1 summarises key definitions and characteristics from the terms and learning approaches. Based on the above key definitions and characteristics from the terms and learning approaches related to microgames, the proposed definition of microgames in education context is as follows:

Microgames are very small and short games that provide brief engagement and meaningful experience for players, support learning and instruction toward specific objectives, and integrate with existing resources.

Every element of the definition has significant words that are further elaborated in the following paragraphs. The elaboration was synthesised from the underlying terms and learning approaches previously discussed.

- Very small and short games. The games are very simple, straightforward, and focused. It is easy to be directly played for a specific purpose. No prior knowledge and skills related to games are needed in order to play. The rules and conventions are not as complex as regular games. Hence, it is normally a short duration gameplay. 
- Brief engagement. The engagement occurring in microgames is a pithy involvement lasting in minutes. The word brief is more appropriate for expressing conciseness rather than short. Something short is not a guarantee that it is concise.

- Meaningful experience. Educational microgames provide meaningful experiences perceived up to an emotional level. Learning is the focus of an educational game so meaningful is more important than fun. The games can offer immediate feedback during a debriefing process of game-based learning.

- Support learning and instruction. Microgames in an education context are designed, developed, and played specifically for teaching and learning practices. Supporting means that the games are profitable for supplementing, reinforcing, and integrating learning and instruction. As a viable supplement, it enables educators to complete or enhance instructions, empowers learners to master particular topics, and facilitates individuals to stay up-to-date in today's knowledge society.

- Specific objectives. Microgames should be designed for specific learning goals. The micro-content concept is applicable to the design of microgames. A microgame ideally contains only one learning objective.

- Integrate with existing resources. Appropriate use of microgames for learning and instruction needs to be integrated with existing resources. The resources include any materials that could be used for facilitating learning and improving performances. For example, it might be learning tools already used by students and teachers, existing lesson plans and course material, and syllabus as well as curriculum. Moreover, the games are best viewed as a teaching tool and not as a substitute for teachers, trainers, or educators so that should be integrated into the meso and macro structures of learning. For instance, inserting microgames in a regular lesson or using it to supplement the whole lessons in the curriculum.

\section{Examples of microgames in education}

Some examples are presented to demonstrate the kinds of games that fit this definition. There are microgames used for training, teaching, and learning as well as research in different contexts. Several very small games created by users in GeoGebra, which is dynamic mathematics software for all levels of education that brings together geometry, algebra, spreadsheets, graphing, statistics and calculus in one easy-to-use package [39], were also provided. The games were chosen based on the available studies of microgames, and for microgames on the GeoGebra platform, those were selected from different categories of school levels to represent various educational settings. The game examples presented in Table 2.

Table 2 presents microgame examples. The first column shows microgames's profile followed by the content, genre, and context, and platform. Looking at the examples into more details, the Yard Crane Scheduler microgame has been employed by Lukosch [3] for training-based situated learning in the work environment. The main task of this 8to-10 minutes game is to manage the yard by aligning the interdependent planning tasks and resource allocation activities in the container terminal. There are two focused main challenges in this microgame - the dynamic planning and distribution of containers in 
the yard and the allocation of resources to ensure maximum utilization. Therefore, this web-based game answers the need for a dynamic representation of a complex problem and for flexible situated learning approaches in complex working environments. The microgame is relatively simple lasting no more than 10 minutes, fruitful for supporting the transfer of learning into the workplace. In addition, this game provides brief engagement and meaningful experience as it dynamically represents the complicated problems in multiplex workplaces.

Table 2. Examples of microgames

\begin{tabular}{|c|c|c|c|c|}
\hline Game & Content & Genre & Context & Platform \\
\hline $\begin{array}{l}\text { Yard Crane Scheduler } \\
\text { Studied by Lukosch et al. (2016) }\end{array}$ & Yard management & Strategy & Corporation & Whitebox \\
\hline $\begin{array}{l}\text { Orbis Pictus Bestialis or Kvido } \\
\text { Studied by Brom et al. (2011) }\end{array}$ & Animal training & Simulation & High school & Computer application \\
\hline $\begin{array}{l}\text { VeGame } \\
\text { Studied by: Bellotti et al. (2004) }\end{array}$ & City exploration & Adventure & $\begin{array}{l}\text { General } \\
\text { public }\end{array}$ & Mobile application \\
\hline $\begin{array}{l}\text { Four-by-Four NIM } \\
\text { Created by Duane Habecker (2017) } \\
\text { GeoGebra link: https://www.geoge- } \\
\text { bra.org/m/j5dHN9dt } \\
\text { Perma link: https://perma.cc/7P7E- } \\
\text { 5RUR }\end{array}$ & $\begin{array}{l}\text { Mathematical } \\
\text { strategy }\end{array}$ & Puzzle & $\begin{array}{c}\text { Elementary } \\
\text { school }\end{array}$ & GeoGebra \\
\hline $\begin{array}{l}\text { Proof Without Words } \\
\text { Created by Steve Phelps (2015) } \\
\text { GeoGebra link: } \underline{\text { https://www.geoge- }} \\
\text { bra.org/m/ZFTGX57r } \\
\text { Perma link: } \underline{\text { https://perma.cc/86F3- }} \\
\text { D4J5 }\end{array}$ & $\begin{array}{l}\text { Pythagorean theo- } \\
\text { rem }\end{array}$ & Simulation & $\begin{array}{l}\text { Middle } \\
\text { school }\end{array}$ & GeoGebra \\
\hline $\begin{array}{l}\text { Log War } \\
\text { Created by John Golden (2015) } \\
\text { GeoGebra link: https://www.geoge- } \\
\text { bra.org/m/g36WySNY } \\
\text { Perma link: } \\
\text { https://perma.cc/YMV7-MRS2 }\end{array}$ & Logic & Strategy & High school & GeoGebra \\
\hline $\begin{array}{l}\text { The Music Note Quiz } \\
\text { Created by Florian Sonner (2012) } \\
\text { GeoGebra link: } \underline{\text { https://www.geoge- }} \\
\text { bra.org/m/gUG8tadS } \\
\text { Perma link: https://perma.cc/BB4Q- } \\
\text { FCB4 }\end{array}$ & Music notes & Quiz & $\begin{array}{c}\text { College and } \\
\text { university }\end{array}$ & GeoGebra \\
\hline
\end{tabular}

The Orbis Pictus Bestialis or Kvido microgame was developed and utilised by Brom [1] for quasi-experimental study in school settings. It has been designed to reinforce and integrate part of the knowledge learnt in the formal instruction. The game is integrated within the traditional lecture. This animal trainer microgame is a single-player game that has three levels. The student has to train an animal to perform a task in each level, for example, to train a dog waving one front leg on a verbal stimulus, to train a lemur entering into a transportation box and closing the door behind it, and to train a parrot speaking. Throughout the 20-minute gameplay, students are practicing basic training techniques such as behaviour capturing, shaping, and chaining, and learning 
how to use a clicker during the training. In these microgames, the games are integrated to the meso structures of learning in a formal manner for supplementing, reinforcing, and integrating learning and instruction.

VeGame stands for Venice Game and is a series of very small games aimed at exploring the city of Venice to gain a better understanding and appreciation of cultural heritage around the city. The general public, particularly young adults aged between 18 and 35 years, are the targeted players. Studied by Bellotti [4], the microgames are categorized based on the cognitive skills including observation, reflection, and arcade games. In addition, VeGame features three main learning modalities: learning by doing (playing), learning by thinking, and learning through social interaction. Each game has specific activities that promote certain skills, for example, one of the games called HistoricalQuiz, stimulates critical reasoning and evaluation of alternatives. The quiz does not rely on previous knowledge, but it stimulates reasoning based on clues provided in the game. In this case, the series of microgames are interrelated with each other within the topic of Venice's cultural heritage so it can be a complete learning space.

The next examples are GeoGebra user-generated microgames. Developed by Duane Habecker in 2017, Four-by-Four NIM is a focused-mathematical-strategy puzzle for elementary school level. It must be played by two players taking turns removing at least one square and the final aim is to avoid or take the last square. Steve Phelps produced Proof Without Words in 2015 as a Pythagorean theorem simulation for middle school students. The game stimulates a fundamental relation in Euclidean geometry among three sides of a right triangle. Log War, created by John Golden in 2015, promotes logical thinking skills in high school. Players should correctly predict which logarithms have a higher number during playing. The Music Note Quiz is a quiz about music notes for college and university made by Florian Sonner in 2012. Entering the name of the music notes into text fields under the notes is its main gameplay. All mentioned games are very simple and easy to be directly played. Although no prior knowledge and skills related to the game are needed in order to play the games, players could have brief engagement and meaningful experience when playing. Those microgames are promising for mathematics learning as other general serious games that are evidently effective for orchestrating knowledge acquisition in mathematics subject [40] or for supporting education in general [41].

Overall, the given microgame examples are very simple, straightforward, and focused. They may support learning and instruction within a specific objective as well as provide brief engagement and meaningful experience in various learning environments. The games require integration into existing learning resources. The use of microgames for educational purposes should be integrated into a meso and/or macro structure of learning in formal, informally, or non-formal ways. Integration thus is a critical part of microgames utilisation for learning. Reflecting on the profile and in particular characteristics of the microgame examples is inline with the proposed conceptual definition of microgames in education. 


\section{Conclusion}

The definition of microgames has been developed from the literature by considering related educational terms and approaches followed by an elaboration of the key definition elements. Furthermore, some examples were provided to illustrate that the definition is properly functioning. The proposed definition mediates the definitions of microgames between Brom [1] and Lukosch [3]. The microgames definition in this study covers various contexts both in workplaces and schools conveying that microgames are acceptable in various learning settings. As games in general [22], microgames could be a system in which players engage in a brief artificial conflict defined by rules that results in a quantifiable specific outcome.

Integration is the most critical aspect of applying microgames for learning purposes. It appears to be meaningless harnessing the games for teaching and learning processes without some connections to existing resources. Microgames in practice, as microlearning [34] and serious games [26], should be integrated into meso and macro structures of learning in formal, informally, or non-formal means. For instance, it could be integrated into learning tools already used by students and teachers, existing lesson plans and course material, or syllabus and curriculum. The games are not a complete learning ecosystem and wholesale replacement for other learning initiatives. It is best viewed as a teaching tool and not a substitute for teachers, trainers, and educators in general.

There is no definite game-play time that is universally recognized for the short duration of microgames. The Orbis Pictus Bestialis game duration is twice as long as the Yard Crane Scheduler game whilst many small games in GeoGebra activity lasting in different time frames. Apart from the duration, it is more important to keep the games as simple, straightforward, and focused as it could be since the engagement in microgames is a kind of concise participation occurring in a few minutes. The more uncomplicated the games, the more powerful engagement might arise.

Finally, the definition of microgames would evolve over time and become gradually refined as a result of continual research. As a conceptual paper, this article has some limitations. The definitions are based on a simple literature review from relevant journals and textbooks without specific criteria. Conducting a systematic literature review combined with a meta-analysis thus could be beneficial to provide an evidence-based definition. Moreover, having a semantic analysis can be another way to propose a definition by drawing meanings from sentences, paragraphs, or full-text of relevant literature. Investigating performances of some microgames in supporting learning and instruction could also be of further research interest. For example, examining the ability of microgames to support a particular level of learning within Bloom's taxonomy.

\section{$7 \quad$ Acknowledgment}

The publication of this article was supported by Johannes Kepler Open-Access Publishing Fund. 


\section{References}

[1] Brom, C., Preuss, M., \& Klement, D. (2011). Are educational computer micro-games engaging and effective for knowledge acquisition at high-schools? A quasi-experimental study. Computers \& Education, 57(3), 1971-1988. https://doi.org/10.1016/j.compedu. $\underline{2011.04 .007}$

[2] Brom, C., Levčík, D., Buchtová, M., \& Klement, D. (2015). Playing educational microgames at high schools: Individually or collectively? Computers in Human Behavior, 48, 682-694. https://doi.org/10.1016/j.chb.2015.02.025

[3] Lukosch, H., Kurapati, S., Groen, D., \& Verbraeck, A. (2016). Microgames for situated learning: A case study in interdependent planning. Simulation \& Gaming, 47(3), 346-367. https://doi.org/10.1177/1046878116635468

[4] Bellotti, F., Berta, R., De Gloria, A., Ferretti, E., \& Margarone, M. (2004). Microgames for a compelling interaction with the cultural heritage. Archives \& Museum Informatics, 2, 116.

[5] Van Rosmalen, P., Boyle, E. A., Van der Baaren, J., Kärki, A. I., \& del Blanco Aguado, Á. (2014). A case study on the design and development of minigames for research methods and statistics. EAI Endorsed Transactions on Game-Based Learning, 1(3), e5. https://doi.org/ $\underline{10.4108 / \text { sg.1.3.e5 }}$

[6] Microgame. (2019). In Wikipedia. Retrieved from https://en.wikipedia.org/w/index.php?ti$\underline{\text { tle}}=$ Microgame $\&$ oldid $=894788198$

[7] Microgame. (n.d.). Retrieved 30 December 2019, from Super Mario Wiki website: https://www.mariowiki.com/Microgame

[8] Stolovitch, H. D. (1978). Minigames and microgames for everyone. Audiovisual Instruction, 23(5), 18-20.

[9] Rahmadi, I. F., Lavicza, Z., Arkün Kocadere, S., Houghton, T., \& Hohenwarter, M. (2021). The strengths and weaknesses of user-generated microgames for assisting learning. Education and Information Technologies. https://doi.org/10.1007/s10639-021-10635-8

[10] Rahmadi, I. F., Lavicza, Z., \& Houghton, T. (2021). Towards User-generated Microgames for Supporting Learning: An Investigative Exploration. Contemporary Educational Technology, 13(3), 1-16. https://doi.org/10.30935/cedtech/10785

[11] Rice, J. W. (2007). New Media Resistance: Barriers to Implementation of Computer Video Games in the Classroom. Journal of Educational Multimedia and Hypermedia, 16(3), 249261.

[12] Ketelhut, D. J., \& Schifter, C. C. (2011). Teachers and Game-based Learning: Improving Understanding of How to Increase Efficacy of Adoption. Computers \& Education, 56(2), 539-546. https://doi.org/10.1016/j.compedu.2010.10.002

[13] Watson, W., \& Yang, S. (2016). Games in Schools: Teachers' Perceptions of Barriers to Game-based Learning. Journal of Interactive Learning Research, 27(2), 153-170.

[14] Micro. In The Merriam-Webster.com Dictionary. Retrieved December 23, 2019, from https://www.merriam-webster.com/dictionary/micro

[15] Micro. In Dictionary.com. Retrieved 30 December 2019, from Www.dictionary.com website: https://www.dictionary.com/browse/micro

[16] Dopfer, K., Foster, J., \& Potts, J. (2004). Micro-meso-macro. Journal of Evolutionary Economics, 14(3), 263-279. https://doi.org/10.1007/s00191-004-0193-0

[17] Li, B. (2012). From a Micro-Macro Framework to a Micro-Meso-Macro Framework. In S. H. Christensen, C. Mitcham, B. Li, \& Y. An (Eds.), Engineering, Development and Philosophy (Vol. 11, pp. 23-36). Springer Netherlands. https://doi.org/10.1007/978-94-007-5282$\underline{52}$ 
[18] Hug, T. (2005). Micro Learning and Narration. Exploring possibilities of utilization of narrations and storytelling for the designing of" micro units" and didactical micro-learning arrangements. In fourth Media in Transition conference (Vol. 6, No. 8). MIT.

[19] Hug, T., \& Friesen, N. (2007). Outline of a microlearning agenda. In Didactics of Microlearning. Concepts, Discourses and Examples (pp. 15-31).

[20] McKinsey, J. C. C. (1952). Introduction to the Theory of Games. New York: The RAND Corporation.

[21] Caillois, R. (1961). Man, play, and games. New York: Free Press.

[22] Salen, K., Tekinbaş, K. S., \& Zimmerman, E. (2004). Rules of play: Game design fundamentals. MIT press.

[23] Garris, R., Ahlers, R., \& Driskell, J. E. (2002). Games, motivation, and learning: A research and practice model. Simulation \& Gaming, 33(4), 441-467. https://doi.org/10.1177/ 1046878102238607

[24] Richey, R. (Ed.). (2013). Encyclopedia of terminology for educational communications and technology. New York: Springer.

[25] Abt, C. C. (1970). Serious games. New York: Viking.

[26] Michael, D. R., \& Chen, S. L. (2005). Serious games: Games that educate, train, and inform. Muska \& Lipman/Premier-Trade.

[27] Dörner, R., Göbel, S., Effelsberg, W., \& Wiemeyer, J. (2016). Introduction. In R. Dörner, S. Göbel, W. Effelsberg, \& J. Wiemeyer (Eds.), Serious Games (pp. 1-34). https://doi.org/ $\underline{10.1007 / 978-3-319-40612-1 \quad 1}$

[28] de Freitas, S. I. (2006). Using games and simulations for supporting learning. Learning, Media and Technology, 31(4), 343-358. https://doi.org/10.1080/17439880601021967

[29] Mildner, P., \& 'Floyd' Mueller, F. (2016). Design of Serious Games. In R. Dörner, S. Göbel, W. Effelsberg, \& J. Wiemeyer (Eds.), Serious Games (pp. 57-82). https://doi.org/10.1007/ 978-3-319-40612-1 3

[30] Susi, T., Johannesson, M., \& Backlund, P. (2007). Serious Games: An Overview. Institutionen för kommunikation och information, University of Skövde.

[31] Bellotti, F., Berta, R., \& De Gloria, A. (2010). Designing Effective Serious Games: Opportunities and Challenges for Research. International Journal of Emerging Technologies in Learning (IJET), 5(SI3). https://doi.org/10.3991/ijet.v5s3.1500

[32] Kangas, M., Koskinen, A., \& Krokfors, L. (2016). A qualitative literature review of educational games in the classroom: The teacher's pedagogical activities. Teachers and Teaching, 1-20. https://doi.org/10.1080/13540602.2016.1206523

[33] Routledge, H. (2009). Games-Based Learning in the Classroom and How it can Work! In Games-based learning advancements for multi-sensory human computer interfaces: Techniques and effective practices (pp. 274-286). IGI Global. https://doi.org/10.4018/978-160566-360-9.ch016

[34] Kapp, K., \& DeFelice, R. (2019). Microlearning: Short and sweet. Alexandria: ATD Press.

[35] Giurgiu, L. (2017). Microlearning an evolving elearning trend. Scientific Bulletin, 22(1), 18 23. https://doi.org/10.1515/bsaft-2017-0003

[36] Buchem, I., \& Hamelmann, H. (2010). Microlearning: A strategy for ongoing professional development. ELearning Papers, 21(7), 1-15.

[37] Jomah, O., Masoud, A. K., Kishore, X. P., \& Aurelia, S. (2016). Micro learning: A modernized education system. BRAIN. Broad Research in Artificial Intelligence and Neuroscience, 7(1), 103-110.

[38] Kimani, S., Catarci, T., \& Gabrielli, S. (2006). The Design of MicroLearning Experiences: A Research Agenda (On Microlearning). In T. Hug, M. Lindner, \& P. A. Bruck (Eds.), Microlearning: Emerging Concepts, Practices and Technologies after e-Learning (1st ed., pp. 45-53). Innsbruck University Press. https://doi.org/10.4324/9780367821623-5 
[39] About GeoGebra. (2020, January 14). GeoGebra. https://www.geogebra.org/about

[40] Pratama, L. D., \& Setyaningrum, W. (2018). GBL in Math Problem Solving: Is it Effective? International Journal of Interactive Mobile Technologies (IJIM), 12(6), 101. https://doi.org/ $10.3991 /$ ijim.v12i6.8658

[41] Liu, Z.-Y., Shaikh, Z. A., \& Gazizova, F. (2020). Using the Concept of Game-Based Learning in Education. International Journal of Emerging Technologies in Learning (IJET), 15 (14), 53. https://doi.org/10.3991/ijet.v15i14.14675

\section{Authors}

Imam Fitri Rahmadi is a $\mathrm{PhD}$ researcher at the Department of STEM Education, Linz School of Education, Johannes Kepler Universität Linz Austria and a lecturer at Universitas Pamulang Indonesia. Educational technology integration into learning and instruction is his overall research interest. In his $\mathrm{PhD}$ research, he explores the potential of user-generated microgames for supporting STEAM learning. He is an awardee of the Indonesia-Austria Scholarship Programme (IASP), a joint scholarship between the Indonesian Ministry of Education and Culture (KEMDIKBUD) and Austria's Agency for Education and Internationalisation (OeAD-GmbH) in cooperation with ASEAN European Academic University Network (ASEA-UNINET).

Zsolt Lavicza is a university professor in STEM education research methods at the Department of STEM Education, Linz School of Education, Johannes Kepler Universität Linz Austria. He has worked on several research projects examining technology and mathematics teaching in classroom environments in Michigan and Cambridge. In addition, he has greatly contributed to the development of the GeoGebra community and participated in developing research projects on GeoGebra and related technologies worldwide. From the Johannes Kepler Universität Linz, he is working on numerous research projects worldwide related to technology integration into schools; leading the doctoral programme in STEM Education; teaching educational research methods worldwide; and coordinates research projects within the International GeoGebra Institute.

Tony Houghton is a visiting professor at the Department of STEM Education, Linz School of Education, Johannes Kepler Universität Linz Austria. His STEAM focus is creative, collaborative problem solving and perception shift originally inspired by industry best practice and since applied to educational projects. He is also Visiting Professor School of Computer Science and Electronic Engineering, University of Essex and a member of the University of Cambridge, Magdalene College with a degree in Psychology and a doctorate in Communications Engineering from University College, London, a year of which was undertaken with Massachusetts Institute of Technology Media Lab (MIT). He has worked with BT, Microsoft, CISCO, Pepsico, DHL, Essex County Council, Aerospatiale, CRICA, ERGOS, EDF, Eurescom, IET, STEMNET, Nationwide, Chunghwa Telecom and Sony in Singapore.

Article submitted 2021-01-04. Resubmitted 2021-08-03. Final acceptance 2021-08-06. Final version published as submitted by the authors. 